\title{
Anemia, iron status, and associated protective and risk factors among children and adolescents aged 3 to 19 years old from four First Nations communities in Quebec
}

\author{
Emad Tahir ${ }^{1,2}$ (D) Pierre Ayotte ${ }^{1,2,3} \cdot$ Matthew Little ${ }^{2,4} \cdot$ Richard E. Bélanger $^{2,5} \cdot$ Michel Lucas $^{1,2} \cdot$ Donna Mergler $^{6}$. \\ Elhadji A. Laouan Sidi ${ }^{1}$. Community of Winneway - Long Point First Nation, Community of Lac Simon, CSSS \\ Tshukuminu Kanani of Nutashkuan, Community of Unamen Shipu • Nancy Gros-Louis McHugh ${ }^{7}$. \\ Mélanie Lemire ${ }^{1,2,8}$
}

Received: 14 May 2019 / Accepted: 13 February 2020 / Published online: 13 March 2020

(C) The Author(s) 2020

\begin{abstract}
Objectives Anemia and iron deficiency (ID) are frequent among Indigenous children of Canada, but few data are available in Quebec. The present study aimed to characterize anemia and ID prevalence and associated protective and risk factors among First Nations youth in Quebec.

Methods The 2015 First Nations (JES!-YEH!) pilot study was conducted among children and adolescents (3 to 19 years; $n=198)$ from four First Nations communities in Quebec. Blood and urine samples and anthropometric measurements were collected. Hemoglobin $(\mathrm{Hb})$, serum ferritin (SF), plasma hs-CRP, and urinary cotinine levels were measured. Factors associated with anemia and ID (including traditional and market food consumption) were assessed using an interview-administered food frequency questionnaire, based on which nutritional intakes were calculated. Structural equation models were used to test associations.

Results The prevalence of anemia and ID was elevated (16.8\% and 20.5\% respectively). Traditional meat, fruit, and fruit juice (natural and powdered)_via their positive association with vitamin $\mathrm{C}$ intake - were the only food variables positively associated with SF (coefficient [95\% CI] 0.017 [0.000, 0.114]; 0.090 [0.027, 0.161]; and 0.237 [0.060, 0.411]). Male sex was also associated with higher $\mathrm{SF}(0.295$ [0.093, 0.502]). Inflammation status (hs-CRP $>5 \mathrm{mg} / \mathrm{L})$ was inversely associated with $\mathrm{Hb}(-0.015[-0.025,-0.005])$, whereas SF was positively associated with $\mathrm{Hb}(0.066[0.040,0.096])$. Fruit and juice consumption was also positively associated with $\mathrm{Hb}$, via vitamin $\mathrm{C}$ intake and SF (0.004 [0.001, 0.010]; 0.008 [0.003, 0.017]).

Conclusions Interventions fostering healthier food environments as well as higher consumption of traditional meats and foods naturally rich in vitamin $\mathrm{C}$, which is known to enhance iron absorption, and fighting inflammation could contribute to decrease the high prevalence of anemia and ID in this young Indigenous population.
\end{abstract}

Electronic supplementary material The online version of this article (https://doi.org/10.17269/s41997-020-00304-7) contains supplementary material, which is available to authorized users.

Mélanie Lemire

melanie.lemire@crchudequebec.ulaval.ca

1 Département de médecine sociale et préventive, Université Laval, Quebec City, QC, Canada

2 Axe santé des populations et pratiques optimales en santé, Centre de recherche du CHU de Québec, Université Laval, Quebec City, QC, Canada

3 Centre de toxicologie du Québec, INSPQ, Quebec City, Canada

4 School of Public Health and Social Policy, University of Victoria, Victoria, Canada
5 Département de pédiatrie, Université Laval, Quebec City, QC, Canada

6 CINBIOSE, Université du Québec à Montréal, Montreal, QC, Canada

7 First Nations of Québec and Labrador Health and Social Services Commission, Wendake, QC, Canada

8 Centre de Recherche du CHU de Québec, Hôpital du Saint-Sacrement, 1050 chemin Sainte-Foy, Quebec City, QC G1S 4L8, Canada 


\section{Résumé}

Objectifs L'anémie et la carence en fer sont fréquentes chez les enfants autochtones au Canada, mais peu de données sont disponibles au Québec. La présente étude visait à caractériser la prévalence de l'anémie et de la carence en fer et les facteurs protecteurs et des risques associés chez des jeunes des Premières Nations du Québec.

Méthodes En 2015, l'étude pilote Jeunes Environnement et Santé (JES! - YEH!) a été menée chez des enfants et des adolescents (3 à 19 ans, $n=198$ ) de quatre communautés de Premières Nations au Québec. Des échantillons de sang et d'urine et des mesures anthropométriques ont été recueillis. Les concentrations d'hémoglobine, de ferritine sérique, de hs-CRP plasmatique et de cotinine urinaire ont été mesurées. Les facteurs associés à l'anémie et à la carence en fer (y compris la consommation d'aliments traditionnels et de marché) ont été évalués à l'aide de questionnaires de fréquences alimentaires administré par un assistant de recherche, à partir desquels les apports nutritionnels ont été calculés. Des modèles d'équations structurelles ont été utilisés pour tester les associations.

Résultats La prévalence de l'anémie et de la carence en fer était élevée (16,8\% et 20,5\% respectivement). La viande traditionnelle, les fruits et les jus de fruits (naturels et en poudre) - par l'intermédiaire de leur association positive avec l'apport en vitamine $\mathrm{C}$ - étaient les seules variables alimentaires positivement associées à la ferritine sérique (coefficient [IC à $95 \%]$ : $0,017[0,000,0,114] ; 0,090[0,027,0,161]$; et $0,237[0,060,0,411]$ ). Le sexe masculin était également associé à une ferritine sérique plus élevée $(0,295[0,093,0,502])$. Le statut inflammatoire (hs-CRP $>5 \mathrm{mg} / \mathrm{L}$ ) était inversement associé à l'hémoglobine $(-0,015[-0,025,-0,005])$ alors que la ferritine sérique était positivement associée à l'hémoglobine $(0,066[0,040,0,096])$. La consommation de fruits et de jus était aussi positivement associée à l'hémoglobine via l'apport en vitamine $\mathrm{C}$ et la ferritine sérique $(0,004[0,001,0,010] ; 0,008[0,003,0,017])$.

Conclusions Les interventions favorisant des environnements alimentaires plus sains ainsi qu'une consommation plus élevée de viandes et d'aliments traditionnels naturellement riches en vitamine $\mathrm{C}$, qui sont connus d'améliorer l'absorption de fer, ainsi que luttant contre l'inflammation pourraient contribuer à diminuer la prévalence élevée d'anémie et de la carence en fer dans cette jeune population autochtone.

Keywords Childhood anemia $\cdot$ Iron deficiency $\cdot$ First Nations $\cdot$ Vitamin $C \cdot$ Inflammation

Mots-clés Anémie pédiatrique $\cdot$ Carence en fer $\cdot$ Premières Nations $\cdot$ Vitamine $\mathrm{C} \cdot$ Inflammation

\section{Introduction}

Canada is among countries with the lowest prevalence of childhood anemia. In 2009-2011, 97\% to 99\% of Canadian children and adolescents had sufficient hemoglobin $(\mathrm{Hb})$ levels, which means that less than $3 \%$ of the Canadian youth general population presented anemia (Cooper et al. 2012). However, anemia prevalence is invariably higher among Indigenous populations all over North America (Christofides et al. 2005; Jamieson et al. 2016). Individuals with mild to moderate forms of anemia are physically limited by the fatigability, shortness of breath, dizziness, and muscle weakness due to inadequate tissue supply of oxygen. However, those with severe cases of anemia can progress to heart failure and even death (Turkoski 2003).

Indigenous populations in Canada refer to First Nations, Métis, and Inuit Peoples. They have lived in what is now Canada long before the arrival of Europeans and now make up 5\% of the national population (Statistics Canada 2017). First Nations are the largest group (65\%), with a relatively younger population when compared with non-Indigenous Canadians (Kelly-Scott and Smith 2015). Each First Nation is composed of many communities that share common language, culture, and traditional diet (Chan et al. 2019). In these communities, dietary shifting from traditional foods, largely composed of wild animal, fish, birds, fruits, and plants, to poor-quality market foods lower in iron often results in iron deficiency (ID) (INSPQ 2015) and if severe enough to impair erythropoiesis, to iron deficiency anemia (IDA) (Christofides et al. 2005). Furthermore, inflammation secondary to infection and obesity disturbs $\mathrm{Hb}$ and red blood cell synthesis, and results in anemia of chronic inflammation (ACI) (Jamieson et al. 2016; Cash and Sears 1989). Other vitamin deficiencies, along with lead $(\mathrm{Pb})$ intoxication (at exposure levels above $100 \mu \mathrm{g} / \mathrm{L}$ ), are also known causes of anemia that some researchers in population studies regroup as unexplained anemia (UA) (Christofides et al. 2005; Jamieson et al. 2012; Plante et al. 2011; Hegazy et al. 2010). Other possible causes of anemia are hemorrhagic, hemolytic, and anemia linked to hemoglobinopathies, although they are all less common in First Nation contexts (Jamieson and Kuhnlein 2008).

Worldwide, ID is the most common nutritional deficiency (de Benoist et al. 2008; WHO 2001). ID has detrimental side effects such as reduced memory and attention, defective thermoregulatory mechanisms, and defective immunity (Lopez et al. 2016). It may occur directly from inadequate iron intake, or indirectly due to reduced intestinal absorption rate of iron. Contrary to iron from animal meats (heme iron) that has 
superior bioavailability, the intestinal absorption of non-heme iron, found in fruits, vegetables, and cereals, is influenced positively by increased gastric acidity and concurrent intake of iron-absorption enhancers (vitamin C, vitamin A, and proteins from animal meats) (WHO 2001). Conversely, the intake of iron-absorption inhibitors (dairy products, tea, egg protein, etc.) prevents non-heme iron absorption (WHO 2001). Moreover, bacterial and parasitic infections such as Helicobacter pylori, which is common in regions facing precarious housing conditions and poor hygiene, reduce gastric acidity and then decrease non-heme iron absorption. Also, $H$. pylori infection further contributes to ID as a result of intestinal bleeding (Jamieson and Kuhnlein 2008).

Data on anemia and ID prevalence are scarce in First Nations youth in Canada as First Nations populations are not included in the Canadian Health Measures Survey (CHMS) (St-Amand 2017). Moreover, the very few existing studies on anemia and ID among First Nations are limited to preschool children and adult populations (Christofides et al. 2005). Thus, the present study aimed to document the prevalence of anemia and ID and their associations with possible protective and risk factors among children and adolescents (3-19 years) from two Anishinabe and two Innu communities in Quebec.

\section{Materials and methods}

\section{Study population}

The Jeunes, Environnement et Santé/Youth, Environment and Health (JES!-YEH!) pilot project is a cross-sectional study realized in 2015 in collaboration with two Innu and two Anishinabe First Nations communities that involved 198 participants aged 3 to 19 years old. The aim of the JES!-YEH! pilot study was to document exposure to environmental contaminants, nutritional and health status, and other health determinants in First Nation children and young adults. Further details can be found in CaronBeaudoin et al. (2019). The two First Nations targeted for the study were selected in collaboration with study partners at the First Nations of Quebec and Labrador Health and Social Services Commission (FNQLHSSC), primarily to represent two distinct ecological regions of the Quebec province (Fig. 1). The AbitibiTémiscamingue is an inland region with multiple lakes in Northwest Quebec. It is the natural habitat of several wildlife species, such as freshwater fish, moose, beaver, and black bears, and a region characterized by several mining, forestry, and agricultural activities. The Minganie and Lower-North-Shore comprise a large coastal region in Northeast Quebec, where fisheries are the central community and economic activities. All Anishinabe and Innu communities from these two regions with $>500$ children and youth were invited to participate. The four communities participating in the project were involved primarily based on their interest in the pilot study. Field research periods
(May and June 2015 for Anishinabe communities and September and October 2015 for Innu communities) were selected with community partners to not interfere with hunting and fishing periods as well as other important local events.

This study was approved by the ethical boards of the $C H U$ de Québec-Université Laval (no. C14-08-2105) and Health Canada (no. 2014-0043). Community leaders signed a community research agreement, inspired by the research protocol of First Nations of Quebec and Labrador and respecting the OCAP ${ }^{\circledR}$ (ownership, control, access, and possession) principles (Basile et al. 2014). Communities and FNQLHSSC partners were involved at all steps of the study, including the design, data collection, data interpretation, and presentation of results in the communities and at the regional level, as well as co-authors of the present study. Participants' results for anemia, ID, and other health measurements detailed in Table 1 were returned in person to the participants' parents or legal guardians, and local clinical follow-ups and interventions were undertaken when relevant.

To minimize selection bias, a total of 177 participants were randomly selected out of 279 candidates contacted from the lists of potential participants aged 3 to 19 years old and provided by the four community partners. These were recruited according to the underlying population distribution in each of the four communities ( $3-5$ years, 6-11 years, and 12-19 years for both sexes) based on the 2014 Statistics Canada Census (Government of Canada 2014). To reach our recruitment target, 21 additional participants were recruited on a voluntary basis but in accordance with recruitment targets by age and sex groups. Overall, out of the 198 participants recruited, 95\% of participants $(n=106 / 111)$ from the two Anishinabe communities and $82 \%$ of participants $(n=71 / 87)$ from the two Innu communities were selected on a random basis.

For data collection, parents or legal guardians accompanied study participants aged less than 18 years old in all sessions, while older participants completed all sessions independently. After signing an informed consent form and seeking child verbal assent, two qualified nurses administered a short medical questionnaire and collected anthropometric measurements (height and weight), blood samples (by venipuncture), and a spot urine sample. Then, participants and parents/legal guardians were invited to answer an interview-administered questionnaire including education, housing conditions, and household food security information as well as a traditional and market food frequency questionnaire (FFQ). The entire session lasted approximately $1.5 \mathrm{~h}$. To facilitate recruitment, participants were not asked to fast prior to data collection.

\section{Laboratory analyses}

$\mathrm{Hb}$ concentration was quantified in situ using a $\mathrm{HemoCue} \mathrm{Hb}$ 201+. Biological samples were kept frozen at $-20^{\circ} \mathrm{C}$ until analyzed. Serum ferritin (SF), transferrin saturation (TS), 


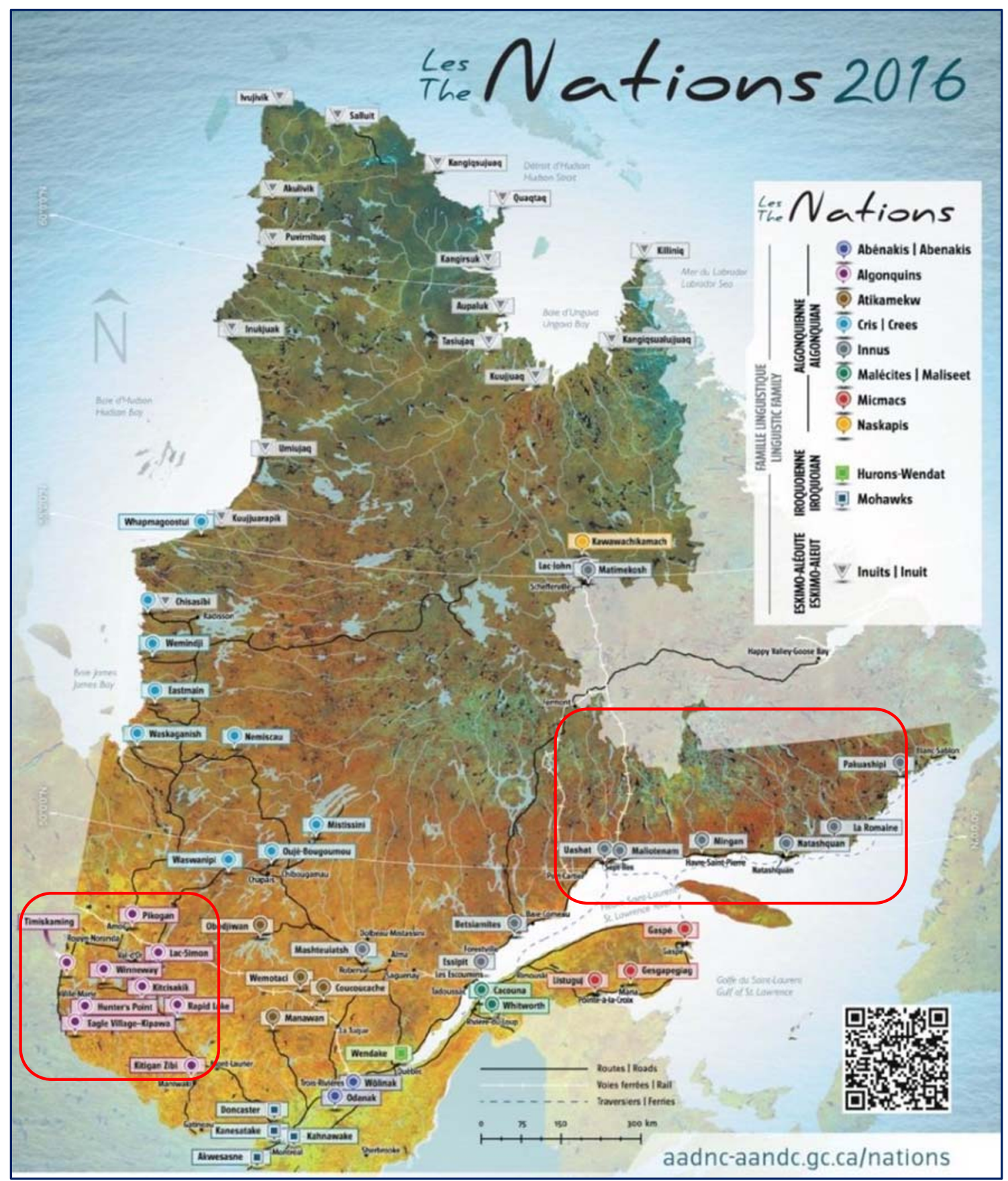

Fig. 1 Map of the Quebec province. The Abitibi-Témiscamingue (left) and Minganie and Lower-North-Shore (right) regions where the study took place are indicated by red rectangles. (For interpretation of the references to colour in this figure legend, the reader is referred to the web version of this article)

serum iron (SI), unsaturated iron binding capacity (UIBC), and plasma hs-CRP (high-sensitivity C-reactive protein) were measured at the Institut Universitaire de Cardiologie et Pneumologie de Québec using Modular P, Modular E170, and Cobas Integra 800 analyzers. The total iron binding capacity (TIBC) was calculated using the sum of UIBC and SI. Blood $\mathrm{Pb}$ was also quantified by inductively coupled plasma mass spectrometry (ICP-MS) at the Centre de Toxicologie $d u$ Québec (CTQ) of the Institut national de santé publique du Québec. Its limit of detection was $<1.04 \mu \mathrm{g} / \mathrm{L}$.

\section{Assessment of anemia and ID}

Anemia was defined as insufficient $\mathrm{Hb}$ based on the World Health Organization (WHO) Hb cutoff values specific to each age group and sex (Fig. 2), and further classified into "mild," "moderate," or "severe" (WHO 2001). Hb concentrations were adjusted by a factor of $-3 \mathrm{~g} / \mathrm{L}$ for active cigarette smokers (urinary cotinine $>100 \mathrm{ng} / \mathrm{mL}$ ) (Nordengberg et al. 1990). No adjustment was made for the altitude given that all study participants were living at sea level (WHO 2001). 
Table 1 Characteristics of all study participants and by nation

\begin{tabular}{|c|c|c|c|c|c|c|}
\hline \multirow[t]{2}{*}{ Variables } & \multicolumn{2}{|c|}{ All participants $(n=191)$} & \multicolumn{2}{|c|}{ Anishinabe $(n=107)$} & \multicolumn{2}{|c|}{ Innu $(n=84)$} \\
\hline & $n$ & GM [min-max] & $n$ & GM [min-max] & $n$ & GM [min-max] \\
\hline \multicolumn{7}{|l|}{ Continuous variables } \\
\hline Age (years) ${ }^{\mathrm{a}}$ & 191 & $10.3[3,19]$ & 107 & $9.8[3,19]$ & 84 & $10.6[3,19]$ \\
\hline BMI & 189 & $24.0[14.3,64.7]$ & 107 & $20.7[14.3,37.8]$ & 82 & $26.5[16.1,64.7]^{* *}$ \\
\hline $\mathrm{Hb}(\mathrm{g} / \mathrm{L})$ & 191 & $125.7[60.0,175.0]$ & 107 & $124.6[88.0,166.0]$ & 84 & $125.3[60.0,175.0]$ \\
\hline $\mathrm{SF}(\mu \mathrm{g} / \mathrm{L})$ & 190 & $37.0[2.5,278.3]$ & 107 & $26.0[3.7,146.0]$ & 83 & $31.4[2.5,278.3]$ \\
\hline Plasma hs-CRP (mg/L) & 190 & $2.2[0.0,31.7]$ & 107 & $0.6[0.0,31.7]$ & 83 & $1.3[0.1,18.7]^{* *}$ \\
\hline Blood $\mathrm{Pb}(\mu \mathrm{g} / \mathrm{L})$ & 191 & $5.9\left[\begin{array}{lll}1.78 & 50.4]\end{array}\right]$ & 107 & $5.6[1.8,50.4]$ & 84 & $6.4[2.40,28.60]$ \\
\hline Urinary cotinine $(\mathrm{ng} / \mathrm{mL})$ & 190 & $122.1[0.6,2700.0]$ & 106 & $1.5[0.6,1500.0]$ & 84 & $10.3[0.6,2700]^{* *}$ \\
\hline Categorical variables & $n$ & $\%[95 \% \mathrm{CI}]$ & $n$ & $\%[95 \% \mathrm{CI}]$ & $n$ & $\%[95 \% \mathrm{CI}]$ \\
\hline \multicolumn{7}{|l|}{ Age categories } \\
\hline $3-5$ years & 35 & $18.3[13.5,24.4]$ & 22 & $20.6[14.0,29.2]$ & 13 & $15.5[9.1,24.8]$ \\
\hline $6-11$ years & 77 & $40.3[33.6,47.4]$ & 45 & $42.1[33.1,51.5]$ & 32 & $38.1[28.5,48.8]$ \\
\hline 12-19 years & 79 & $41.4[34.6,48.5]$ & 40 & $37.4[28.8,46.8]$ & 39 & $46.4[36.4,57.0]$ \\
\hline Girls & 93 & $47.1[40.2,54.2]$ & 55 & $48.6[39.3,58.0]$ & 38 & $45.2[36.2,57.0]$ \\
\hline \multicolumn{7}{|l|}{ BMI categories $(n=189)$} \\
\hline Underweight & 2 & $1.1[0.3,3.8]$ & 2 & $1.9[0.5,6.6]$ & 0 & \\
\hline Normal & 59 & $31.2[25.4,38.1]$ & 45 & $42.1[33.1,51.5]^{* *}$ & 14 & $17.1[10.3,26.8]$ \\
\hline Overweight & 52 & $27.5[21.6,34.3]$ & 37 & $34.6[26.2,44.0]^{*}$ & 15 & $18.3[11.4,28.0]$ \\
\hline Obese & 76 & $40.2[33.5,47.3]$ & 23 & $21.5[14.8,30.2]$ & 53 & $64.6[53.8,74.1]^{* *}$ \\
\hline \multicolumn{7}{|l|}{ Parental education } \\
\hline Primary & 46 & $24.1[18.6,30.6]$ & 20 & $18.7[12.4,27.1]$ & 26 & $31.0[22.1,41.5]^{*}$ \\
\hline Secondary & 106 & $55.5[48.4,62.4]$ & 63 & $58.9[49.0,68.3]$ & 43 & $51.2[40.7,61.6]$ \\
\hline College or above & 39 & $20.4[15.3,26.7]$ & 24 & $22.4[15.6,31.2]$ & 15 & $17.9[11.1,27.4]$ \\
\hline Anemia & 32 & $16.8[12.2,22.8]$ & 18 & $16.8[10.9,25.0]$ & 14 & $16.9[10.3,26.3]$ \\
\hline $3-5$ years & 2 & $5.9[1.6,19.1]$ & 1 & $4.6[0.1,21.8]$ & 1 & $8.3[14.9,35.4]$ \\
\hline 6-11 years, girls & 5 & $14.7[6.5,30.1]$ & 3 & $14.3[5.0,34.5]$ & 2 & $15.4[4.3,42.2]$ \\
\hline $6-11$ years, boys & 9 & $20.9[11.4,35.2]$ & 3 & $12.5[4.3,31.0]$ & 6 & $31.6[15.4,54.0]$ \\
\hline $12-19$ years, girls & 10 & $24.4[13.8,39.3]$ & 7 & $33.3[17.2,54.6]$ & 3 & $15.0[5.2,36.0]$ \\
\hline $12-19$ years, boys & 6 & $15.8[7.4,30]$ & 4 & $21.1[8.5,43.0]$ & 2 & $10.5[2.9,31.4]$ \\
\hline \multicolumn{7}{|l|}{ Severity of anemia } \\
\hline Mild & 20 & $10.5[6.9,15.7]$ & 9 & $8.4[4.5,14.2]$ & 11 & $13.6[7.6,22.2]$ \\
\hline Moderate & 11 & $5.8[3.3,10.1]$ & 9 & $8.4[4.5,15.2]$ & 2 & $2.4[0.7,8.4]$ \\
\hline Severe & 1 & $0.5[0.0,2.9]$ & 0 & & 1 & $1.2[0.2,6.5]$ \\
\hline \multicolumn{7}{|l|}{ Types of anemia } \\
\hline IDA & 16 & $8.4[5.3,13.2]$ & 10 & $9.4[5.2,16.4]$ & 6 & $7.2[3.4,14.9]$ \\
\hline ACI & 12 & $6.3[3.7,10.7]$ & 6 & $5.6[2.6,11.7]$ & 6 & $7.2[3.4,14.9]$ \\
\hline UA & 4 & $2.1[0.8,5.3]$ & 2 & $1.9[0.1,6.6]$ & 2 & $2.4[0.7,8.4]$ \\
\hline ID $(n=190)$ & 39 & $20.5[15.4,26.8]$ & 22 & $20.6[14.0,29.2]$ & 18 & $20.5[13.2,30.4]$ \\
\hline $3-5$ years & 5 & $14.7[6.5,30.1]$ & 5 & $22.7[10.1,43.4]$ & 0 & - \\
\hline 6-11 years, girls & 3 & $8.8[3.1,23.0]$ & 1 & $4.8[0.9,22.7]$ & 2 & $15.4[4.3,42.2]$ \\
\hline 6-11 years, boys & 7 & $16.3[8.1,30.0]$ & 1 & $4.2[0.7,20.2]$ & 6 & $31.6[15.4,54.0]$ \\
\hline $12-19$ years, girls & 18 & $43.9[29.9,59.0]$ & 11 & $52.4[32.4,71.7]$ & 7 & $35.0[18.1,56.7]$ \\
\hline $12-19$ years, boys & 6 & $15.8[7.4,30.4]$ & 4 & $21.1[0.9,43.3]$ & 2 & $10.5[29.0,31.4]$ \\
\hline Inflammatory status (hs-CRP $>5 \mathrm{mg} / \mathrm{L}$ ) & 21 & $11.1[7.3,16.3]$ & 9 & $8.4[4.5,15.2]$ & 12 & $14.5[8.5,23.6]$ \\
\hline $\begin{array}{l}\text { Cigarette smoke exposure } \\
\quad \text { (urinary cotinine }>100 \mathrm{ng} / \mathrm{mL} \text { ) }\end{array}$ & 28 & $14.7[10.4,20.5]$ & 9 & $8.4[4.5,15.2]$ & 19 & $22.6[15.0,32.7]^{* *}$ \\
\hline
\end{tabular}

${ }^{\mathrm{a}}$ Arithmetic mean

$G M$, geometric mean; Min, minimum value; Max, maximum value; $C I$, confidence interval; $B M I$, body mass index; $H b$, hemoglobin; $S F$, serum ferritin; $h s-C R P$, highly sensitive C-reactive protein; $N$, number of participants; $P b$, lead; $I D A$, Iron deficiency anemia; $A C I$, anemia of chronic inflammation; $U A$, unknown anemia; $I D$, iron deficiency

${ }^{*} p$ value $<0.05 ; * * p$ value $<0.01$ for the corresponding $t$ test and $\chi^{2}$ test

ID was assessed based on SF, hs-CRP, and SI levels. Level of SF is a reliable tool to diagnose ID in the absence of inflammation (hs-CRP $\leq 5 \mathrm{mg} / \mathrm{L}$ ); therefore, $\mathrm{SF}$ $<15 \mu \mathrm{g} / \mathrm{L}$ was used to define ID. In the presence of inflammation (hs-CRP $>5 \mathrm{mg} / \mathrm{L}$ ), which is frequent among children and in First Nations context, a correction is necessary and ID was diagnosed with $\mathrm{SF}<50 \mu \mathrm{g} / \mathrm{L}$ (Turgeon O'Brien et al. 2016). Since the maximum level of CRP is reached $48 \mathrm{~h}$ following an acute inflammation and decreases gradually to less than $10 \mathrm{mg} / \mathrm{L}$ in approximately 10 days, a lower cutoff value of $5 \mathrm{mg} / \mathrm{L}$ was used (Turgeon O’Brien et al. 2016). 


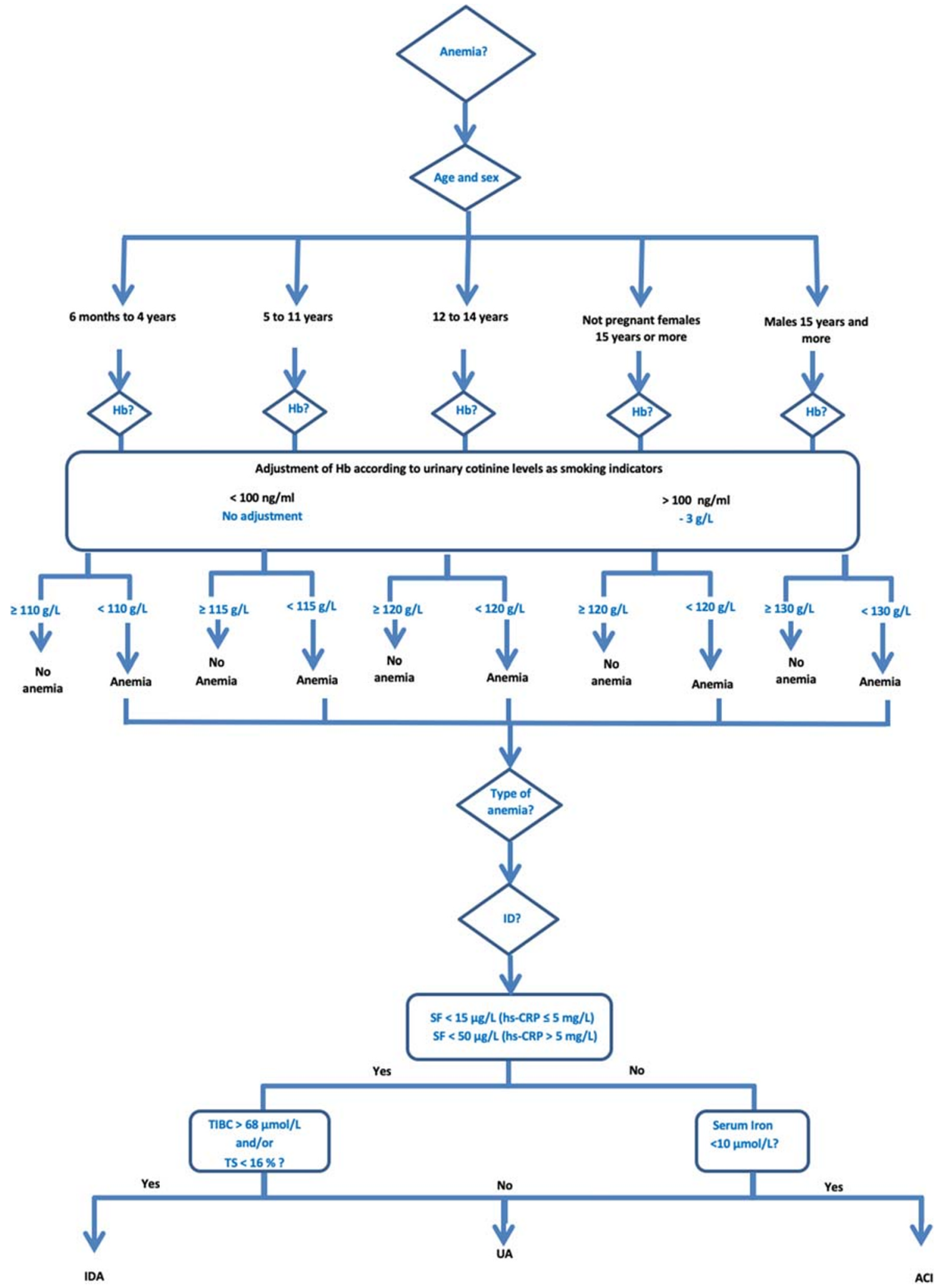

Fig. 2 Algorithm for classification of anemia

Participants with anemia were categorized into IDA, ACI, and UA using multiple-indices model as proposed by Plante et al. (2011). When participants with anemia presented with ID and abnormal TIBC and/or TS $(>68 \mu \mathrm{mol} / \mathrm{L}$ and/or $<16 \%$, respectively), they were categorized as IDA (Cash and Sears 1989). Participants with anemia showing low SI $(<10 \mu \mathrm{mol} / \mathrm{L})$ 
but without evidence of ID were categorized as ACI as low SI is a consistent feature of chronic inflammation (Cash and Sears 1989); otherwise, they were classified as UA (Plante et al. 2011). Participants diagnosed with anemia on the site of the study were readily referred to health centres and community nutritionists for a follow-up. Moreover, participants' results for blood metals and nutritional status were returned in person to the parents or legal guardian, and local clinical interventions were undertaken when relevant.

\section{Statistical analysis}

To respect the normality assumptions, a log-transformation was used for $\mathrm{Hb}$, SF, blood and plasma metals, and dietary intake variables. Descriptive analyses were performed (geometric means (GM), 95\% confidence intervals (CI), or range). The Student $t$ test was used to compare continuous variables, whereas chi-square $\left(\chi^{2}\right)$ was used to compare proportions between nations and sex. Dietary variables with extreme values (outliers) were winsorized to the 97.5 th percentile. Frequently consumed food (fruits, vegetables, and fruit juice, i.e., natural and powdered juice) and nutrient intakes were used as continuous variables in grams per day (method for nutrient intake calculation is detailed in the Supplementary Materials). Less frequently consumed food variables such as wild fish, birds and game meat, beef meat, pork meat, and chicken were dichotomized (above and below their median value since many participants negated their consumption). Protective and risk factors and confounding variables potentially associated with different outcomes (anemia or ID) are listed in Table S1. Height and weight were used to calculate BMI $\left(\mathrm{kg} / \mathrm{m}^{2}\right)$. Since BMI is known to be a less-sensitive single measurement to assess adiposity in children, its $z$-score equivalent to $\pm 2 \mathrm{SD}$ beyond the means of BMI for age and sex was calculated (Cole et al. 2005).

Structural equation modeling (SEM) was preferred over conventional multiple regression analyses since we were interested in better understanding the contribution of direct and indirect paths of variables associated with the outcomes (Nachtigall et al. 2003). SEM is made of two components: (i) a measurement model to assess co-linearity and create latent variables accordingly; and (ii) a structural model to evaluate the correlations between co-variables. The measurement part of SEM is based on confirmatory factor analysis, where correlated variables (Pearson $r>0.40$ ) such as food frequencies or dietary intakes measuring common concepts were identified and combined into single latent variables. To improve models fit, some variables were excluded such as those for infrequently consumed food failing to converge into the latent variables or presenting negligible association with the outcome variables. More details on the complete list of the variables tested and included in the final models are presented in Table S1.
The structural component of SEM is depicted in Fig. 3. First, the magnitude of the associations through direct and indirect paths between protectors and risk factors/latent variables and SF (outcome variable) and via intermediate variables (vitamin $\mathrm{C}$ intake and other vitamins intakes) was evaluated using regression models. Second, a model evaluating the direct paths between independent variables and $\mathrm{Hb}$ (outcome variable) as well as their indirect paths via SF, vitamin $\mathrm{C}$, and other vitamins (intermediate variables) was assessed. The effect of juice consumption was presumed to be exclusively via the vitamin $C$ intake and the other vitamins since processed fruit juices are low in iron and proteins which does not justify a direct path to SF and Hb. Sensitivity analyses testing models stratified by sex and by studied nations were conducted. SEM models fit (provided with data tables in the Supplementary Materials) was assessed based on a $p$ value $>0.05$ ( $\chi^{2}$ test), root means square error of approximation (RMSEA) less than 0.07, Tucker-Lewis fit index (TLI) greater than 0.95, comparative fit index (CFI) greater than 0.95 , and weighted root mean square residual $($ WRMR) > 0.05 (Hooper et al. 2008). The direct and mediated paths were evaluated using the bootstrap method in which random re-sampling with replacement for 10,000 bootstraps was done to improve estimate accuracy. The two-tailed statistical significance level was fixed at 0.05 . The effect of variables was considered significant if $p$ value $<0.05$ and when the coefficient CI did not include zero. Descriptive statistics were done using SAS version 9.4. SEM analysis was conducted using Mplus software, which by default analyze maximum $(n)$ of data using the full information maximum likelihood estimator to account for the few missing values.

\section{Results}

Of the 198 participants recruited, five participants were excluded due to missing blood samples and two participants were excluded due to unrealistic very extreme values in the FFQ.

Anemia and ID prevalences were $16.8 \%$ and $20.5 \%$ respectively (Table 1) and not different between Anishinabe and Innu participants. More than $20 \%$ of 6- to 11 -year-old boys and 12- to 19-year-old girls were classified with anemia and almost half (43.9\%) of girl participants aged 12 to 19 years old displayed ID. Within both First Nations, IDA was the most frequent type of anemia $(n=16 / 32,50.0 \%)$, and in most cases, anemia was classified as mild or moderate.

Obesity, inflammation, and cigarette smoke exposure were higher among Innu than among Anishinabe participants (Table 1). Moreover, SF levels were lower and ID prevalence was higher among female compared with male participants (Table S2). Blood lead levels were higher among Innu and 


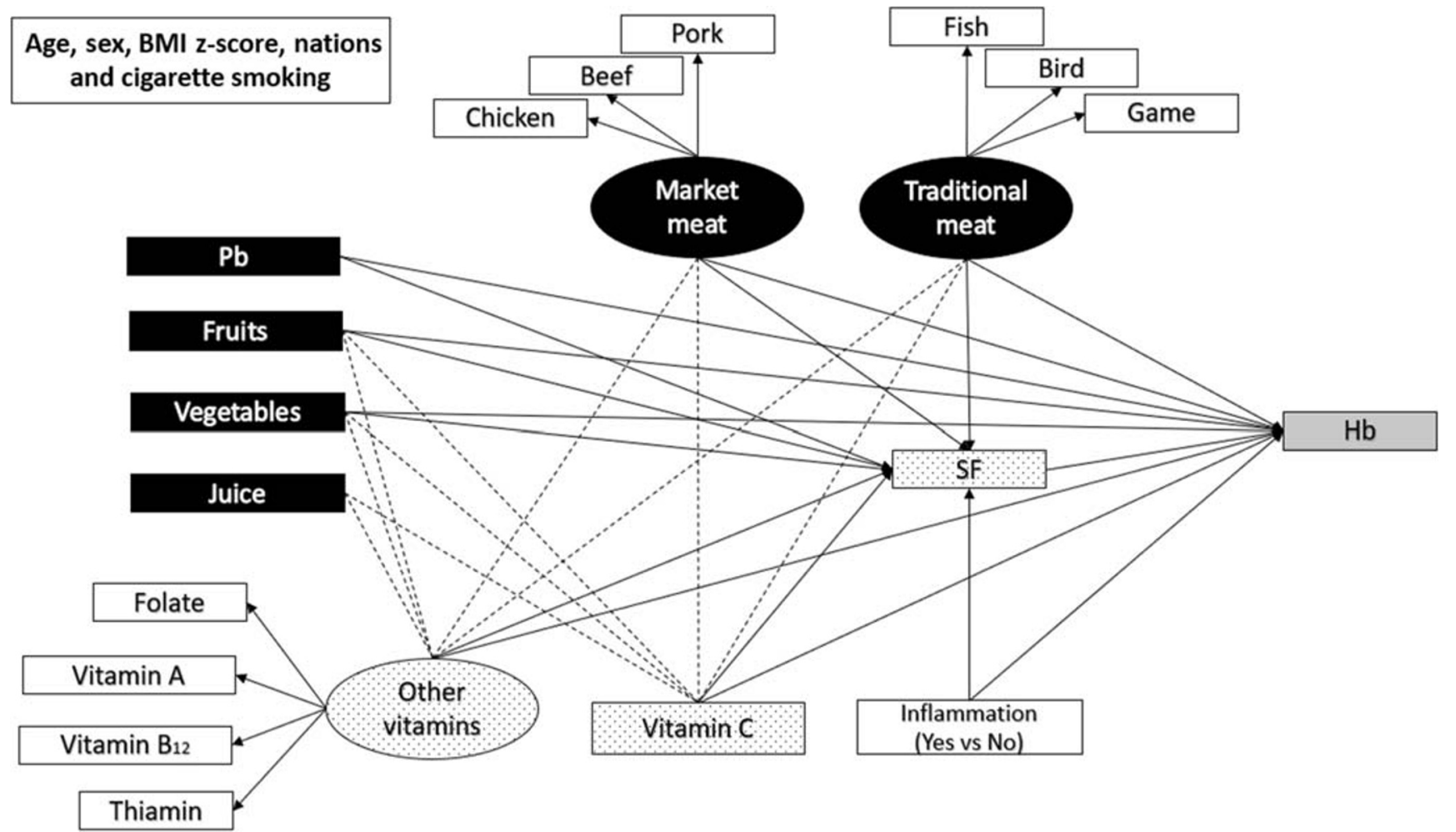

Fig. 3 SEM models 1 and 2, showing measured variables (rectangle boxes), latent variables (oval boxes), their items (white boxes), and their direct and indirect effects tested on SF and $\mathrm{Hb}$. Direct effects of the variables on $\mathrm{Hb}$ and $\mathrm{SF}$ are depicted using uninterrupted lines. Indirect effects are shown using interrupted lines. Gray boxes indicate

male participants (Tables 1 and S2) but more than 10 times lower than those reported to impair erythropoiesis.

As shown in Table 2, market meats were on average over twice more consumed than traditional meats. Wild fish and pork were more consumed among Innu participants, while fruits and vegetables were more consumed by Anishinabe participants. For both studied nations, fruits were more consumed than vegetables. Fruit juice consumption (natural and powdered) was higher than water consumption among Innu participants. No significant difference was observed between nations for total market meats, beef, pork, and chicken intakes, nor for vegetables or juice intakes. With the exception of fruits and pork meat, which were more consumed by girls, other food intakes were not different between sexes (Table S3). More than $90 \%$ of participants had adequate intakes of iron, vitamin $A$, vitamin $B_{12}$, vitamin $C$, folate, and thiamin (Table 2), and no differences between nations or sexes were found (Tables 2 and $\mathrm{S} 3$ ).

Results of models 1 and 2 evaluating the associations between potential protective and risk factors and $\mathrm{SF}$ and $\mathrm{Hb}$ levels are shown in Fig. 4. All significant direct and indirect variable coefficients are detailed in Table S4. Model 1 results of SEM analysis showed that male sex, inflammation, and vitamin C intake were associated with higher SF. Moreover, outcome variables. Black and dotted pattern boxes are predictors and intermediate variables, respectively. No lines were drawn for potentially confounding variables (age, sex, BMI $z$-score, studied nations, and cigarette smoke exposure) since they may affect all associations

vitamin $\mathrm{C}$ intake was found to mediate the positive association between fruit and juice consumption and SF. The direct association between fruit consumption and SF was not statistically significant (data not shown; coefficient for the direct path [95\% CI], -0.009 [-0.296, 0.291]). All other protective and risk factor variables, including food variables rich in iron and/ or proteins, were not directly or indirectly related to SF.

For model 2, cigarette smoking and higher levels of SF were in turn associated with higher $\mathrm{Hb}$ concentrations, whereas inflammation was associated with lower $\mathrm{Hb}$ levels. As for SF, fruit and juice consumptions were positively associated with $\mathrm{Hb}$, mediated via vitamin $\mathrm{C}$ and $\mathrm{SF}$. No significant direct or indirect associations were identified between $\mathrm{Hb}$ and other variables, including blood $\mathrm{Pb}$ levels.

Analogous consistent results with some differences were noticed when stratifying two models by studied nations and by sex (Supplementary Materials Tables S5 and S6). Indeed, the associations mediated by vitamin $\mathrm{C}$ were significant only in girl participants (Table S5). Conversely, among male participants, inflammation status was the main variable associated with $\mathrm{SF}$ and $\mathrm{Hb}$, as was traditional meat consumption with higher Hb via SF. Moreover, girls' age was inversely associated with SF, while the contrary was observed in boys. For models stratified by nations (Table S6), similar trends for fruit and juice 
Table 2 Daily food item consumption and dietary intakes and proportions of participants with adequate dietary intakes for all study participants and by nations

\begin{tabular}{|c|c|c|c|}
\hline $\begin{array}{l}\text { Food and dietary intake } \\
\text { variables (g/day) }\end{array}$ & $\begin{array}{l}\text { All participants }(n=191) \\
\text { GM }[95 \% \mathrm{CI}]\end{array}$ & $\begin{array}{l}\text { Anishinabe }(n=107) \\
\text { GM }[95 \% \text { CI }]\end{array}$ & $\begin{array}{l}\text { Innu }(n=84) \\
\text { GM }[95 \% \mathrm{CI}]\end{array}$ \\
\hline Traditional meats & $28.2[23.5,33.8]$ & $25.2[19.7,32.3]$ & $33.0[25.3,43.0]$ \\
\hline Wild fish & $20.6[16.3,26.1]$ & $15.0[10.5,21.5]$ & $26.8[19.9,36.3]^{*}$ \\
\hline Game & $14.5[11.9,17.7]$ & $15.4[12.0,19.8]$ & $12.5[9.3,16.8]$ \\
\hline Wild birds & $13.4[10.9,16.5]$ & $15.0[11.0,20.5]$ & $12.0[9.0,16.0]$ \\
\hline Market meats & $67.6[60.5,75.6]$ & $68.7[58.6,80.6]$ & $66.2[56.2,77.8]$ \\
\hline Beef & $22.2[19.5,25.4]$ & $23.0[19.0,27.8]$ & $21.3[17.8,25.6]$ \\
\hline Pork & $14.5[12.7,16.5]$ & $12.3[10.3,14.7$ & $17.8[14.7,21.5]^{* *}$ \\
\hline Chicken & $31.4[27.7,35.7]$ & $34.9[29.2,41.7]$ & $27.9[23.3,33.4]$ \\
\hline Fruits & $184.7[162.8,209.5]$ & $205.4[176.9,238.5]^{*}$ & $161.2[130.1,199.8]$ \\
\hline Vegetables & $64.1[54.8,75.0]$ & $74.6[61.0,91.2]^{*}$ & $53.1[41.5,68.1]$ \\
\hline Juice (mL/day) & $437.8[385.5,497.3]$ & $457.2[391.5,533.8]$ & $413.2[332.5,513.4]$ \\
\hline Water (mL/day) & $398.6[347.3,457.4]$. & $461.0[389.7,545.2]^{*}$ & $327.1[260.3,411.0]$ \\
\hline $\begin{array}{l}\text { Micronutrients intake } \\
\text { (mg/day) }\end{array}$ & $\begin{array}{l}\text { GM }[95 \% \text { CI }] \\
\% \text { Adequate intake }{ }^{\mathrm{a}}\end{array}$ & $\begin{array}{l}\text { GM }[95 \% \text { CI }] \\
\% \text { Adequate intake }\end{array}$ & $\begin{array}{l}\text { GM }[95 \% \text { CI }] \\
\% \text { Adequate intake }\end{array}$ \\
\hline Vitamin A & $\begin{array}{l}851.1[768.8,942.2] \\
94.9\end{array}$ & $\begin{array}{l}851.1[768.8942 .2] \\
96.4\end{array}$ & $\begin{array}{l}772.3[695.9,857.1] \\
92.90\end{array}$ \\
\hline Vitamin $B_{12}$ & $\begin{array}{l}7.9[7.3,8.5] \\
100.0\end{array}$ & $\begin{array}{l}7.8[7.0,8.6] \\
100.0\end{array}$ & $\begin{array}{l}8.1[7.1,9.1] \\
100.0\end{array}$ \\
\hline Folate & $\begin{array}{l}543.4[511.3,577.7] \\
96.4\end{array}$ & $\begin{array}{l}522.2[482.5,565.3] \\
98.2\end{array}$ & $\begin{array}{l}572.4[519.9,630.3] \\
94.0\end{array}$ \\
\hline Thiamin & $\begin{array}{l}2.5[2.4,2.7] \\
100.0\end{array}$ & $\begin{array}{l}2.5[2.4,2.7] \\
100.0\end{array}$ & $\begin{array}{l}2.6[2.3,2.8] \\
100.0\end{array}$ \\
\hline Vitamin C & $\begin{array}{l}214.3[195.7,234.8] \\
96.4\end{array}$ & $\begin{array}{l}226.7[203.9,252.0] \\
97.3\end{array}$ & $\begin{array}{l}199.2[169.9,233.6] \\
95.2\end{array}$ \\
\hline Iron & $\begin{array}{l}17.4[16.3,18.5] \\
99.5\end{array}$ & $\begin{array}{l}17.4[16.0,18.9] \\
100.0\end{array}$ & $\begin{array}{l}17.3[15.7,19.1] \\
98.8\end{array}$ \\
\hline
\end{tabular}

${ }^{a}$ Adequate intake was estimated based on Health Canada reference values on age and sex cutoffs of average intake and adequate intakes based on recommended daily allowances (Health Canada, 2006)

$G M$, geometric mean; $C I$, confidence interval

$* p$ value $<0.05, * * p$ value $<0.01$ for the corresponding $t$ test consumption via vitamin $\mathrm{C}$ intake, sex, and inflammation were observed as in the unstratified models, although in some cases the associations did not reach statistical significance. Cigarette smoke exposure was positively associated with $\mathrm{Hb}$ among Innu participants where its exposure was significantly higher. As in the sex-stratified model, traditional meat consumption was associated with higher SF (but only via vitamin C) and with higher $\mathrm{Hb}$ via vitamin $\mathrm{C}$ and $\mathrm{SF}$ in Anishinabe participants.
Fig. 4 Significant direct associations (not standardized coefficients) between dietary and non-dietary determinants of SF and $\mathrm{Hb}$ (models 1 and 2) for all study participants $(n=191)$. Significance level: ${ }^{\dagger} p$ value $<0.10$, ${ }^{*} p$ value $<0.05, * * p$ value $<0.01$

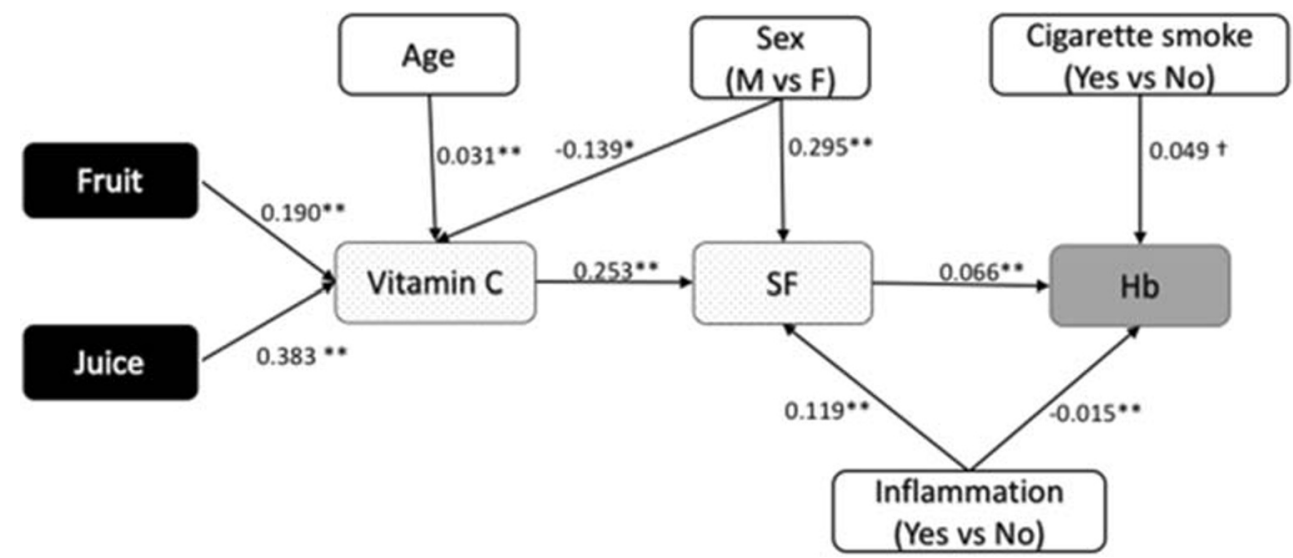




\section{Discussion}

In spite of adequate iron and vitamin intake among most JES!YEH! participants, prevalence of anemia and ID among Anishinabe and Innu participants in 2015 was elevated (16.8\% and $20.5 \%$ respectively), and much higher than in the Canadian general youth population, which was only about 3\% in 2009-2011 (Cooper et al. 2012). These high prevalences are comparable to those reported for other Indigenous children in North America, emphasizing the important health disparities between First Nations and other children in Canada and the United States (Jamieson and Kuhnlein 2008). The WHO considers anemia as a public health problem whenever its prevalence exceeds 5\%. Accordingly and in spite of using capillary blood to determine $\mathrm{Hb}$ using $\mathrm{HemoCue}$ analyzer, which is known to overestimate the $\mathrm{Hb}$ concentrations compared with the complete blood count method (Hinnouho et al. 2018), the anemia prevalence in JES!-YEH! was more than three times this limit. Interestingly, higher traditional meat, fruit, and fruit juice consumption via increased vitamin $\mathrm{C}$ intake and lower inflammation status were the main determinants associated with lower ID and anemia.

In our study, the vast majority of participants with anemia were in the mild or moderate severity categories $(97.0 \%$ of participants with anemia). Nevertheless, considering the systemic impacts of mild-to-moderate hemoglobin deficiency on children's and adolescents' development, addressing underlying factors associated with chronic anemia is important for youth success in school and later in life (Turkoski 2003; Teni et al. 2017). Moreover, low iron status, with or without anemia, which was found in $20.5 \%$ of our study participants, is also known to impair optimal youth development, as it also contributes to lower cognitive functions, thermoregulation, and immunity in children and adolescents (WHO 2001).

The most prevalent type of anemia in our study was IDA. Indeed, as iron is an absolute requirement for $\mathrm{Hb}$ synthesis, IDA is known as a major contributor to childhood anemia burden globally (WHO 2001). The second most prevalent type of anemia was ACI, whereas the prevalence of anemia due to other causes (UA) was relatively low, which is in agreement with the observation that vitamin intakes were adequate in most of the study participants. Other possible causes of anemia such as parasites, hemorrhages, hemolytic anemia, and hemoglobinopathies are possible but were not assessed in the present study.

In the SEM analysis, SF was consistently positively associated with $\mathrm{Hb}$, even after stratification by sex and nations. SF increased with age among boys, but decreased with puberty among girls due to the increasing demands for iron related to blood loss in adolescent girls (WHO 2001). SF was also positively associated with inflammation since SF is an acute phase reactant whose synthesis and release increase during acute inflammation (WHO 2001). Conversely, inflammation was inversely associated with $\mathrm{Hb}$. Indeed, excessive release of inflammatory cytokines is known to impair erythropoietin synthesis and the production of $\mathrm{Hb}$ (Jamieson et al. 2012). It is also known to provoke a functional state of ID, by causing a sequestration of iron in its stores, preventing its transport and utilization, and in turn the integration of iron into $\mathrm{Hb}$ (Hurrell 2012). In the present study, we only used hs-CRP to assess inflammation status. Considering that this biomarker is known to be less sensitive in the case of chronic inflammation (Gruys et al. 2005), which was possibly quite high in our study population considering the very high prevalence of overweight and obesity, the prevalence of inflammation in our study population was likely underestimated. Still, up to $11 \%$ of our study participants presented an inflammatory status, perhaps due to high prevalence of $H$. pylori infection, or chronic ear and upper respiratory tract infections, as observed in another study among preschool Inuit children (Pacey et al. 2011).

In the SEM analysis, our proxy for iron status (SF) was positively associated with vitamin $\mathrm{C}$ intake and, interestingly, vitamin $\mathrm{C}$ acted as a mediator of the positive association between fruit and juice consumption and SF, and ultimately $\mathrm{Hb}$. Vitamin $\mathrm{C}$ plays an important role in iron metabolism (Lane and Richardson 2014). For instance, vitamin C transforms non-heme iron from a ferric state to a more watersoluble and more absorbable ferrous form (WHO 2001; Lane and Richardson 2014). Consequently, vitamin C intake enhances non-heme iron absorption in the small intestine (WHO 2001). Based on the FFQ, most of the participants had sufficient dietary intakes of food containing vitamin $\mathrm{C}$ and iron. Thus, the positive associations between vitamin $\mathrm{C}$ and $\mathrm{SF}$, and then with $\mathrm{Hb}$, possibly reflect a higher vitamin $\mathrm{C}$ requirement due to the high inflammation status in this context (Gruys et al. 2005). Indeed, as reported by Engle-Stone and colleagues (Engle-Stone et al. 2017) in a recent review among preschool children in a high inflammation context, higher rates of ID and IDA were common and primarily related to iron malabsorption issues (EngleStone et al. 2017). It is of note that for vitamin $C$ to increase non-heme iron absorption in food, vitamin C-containing food consumption must be concurrent or shortly after food rich in non-heme iron (WHO 2001; Fishman et al. 1999). Although this information was not captured by FFQ in the present study, we can speculate that greater juice and fruit consumers would likely consume more juice and fruits at mealtimes. Juice was indeed largely consumed by the study participants, and even consumed more often than water.

Despite our small sample size, we found very interesting sex differences. The association mediated by vitamin $\mathrm{C}$ on $\mathrm{SF}$ and $\mathrm{Hb}$ was mainly observed in girls who showed significantly higher intake of vitamin C compared with boys. Conversely, among boys, inflammation was associated with lower $\mathrm{Hb}$, and traditional meat intake was associated with higher $\mathrm{SF}$ and $\mathrm{Hb}$ concentrations. Comparable results were 
reported in adult Inuit men and women, for whom anemia was mainly iron-dependent in premenopausal women but inflammatory-related in men (Jamieson et al. 2016). Inflammation is known to antagonize the absorption of iron mediated by vitamin $\mathrm{C}$ as it enhances hepcidin release and down regulates feroportin1, an iron transporter in the small intestine (Jamieson et al. 2012; Sears 1992). Traditional meats are high in bioavailable iron, proteins, and vitamin $\mathrm{C}$, all associated with positive iron intake and absorption (Jamieson et al. 2012). Interestingly, traditional meat consumption and inflammation status were not different between boy and girl participants, and this highlights the importance of further investigating sex-based differences in iron metabolism concomitantly with other variables such as high inflammation as well as puberty and menstruation in Indigenous youth context.

Aside from the inherent limitations of cross-sectional studies to establish causality, in the present study, the recruitment of few voluntary participants limits the generalization of our results beyond the studied participants. Moreover, the FFQ used in this study presents important limitations as principal care giver responded for younger children without fully knowing what their children eat all day (like snacks provided in school, but the children come home for lunch), particularly in cases where parents were separated. The FFQ may also have led to an underestimation of food and nutrient intakes and further studies should consider using repeated 24-h recalls (Shim et al. 2014), although this represents a significant challenge in remote Indigenous study context when time is limited. Next, in order to classify ACI with no evidence of ID, we used as criterion $\mathrm{SI}<10 \mu \mathrm{mol} / \mathrm{L}$. As a result of non-fasting status prior to data collection, misclassification of some participants with UA as ACI is expected due to higher estimation of SI. Finally, further studies should consider better assessing inflammation status using multiple biomarkers simultaneously (i.e., hs-CRP and alpha1-acid glycoprotein) and documenting sources of chronic inflammation, infections, and blood loss, such as $H$. pylori active infection and menstruation, as well as properly estimating the type of iron in the diet and the timing of vitamin $\mathrm{C}$ intake in respect to meals.

\section{Conclusion}

This pilot project highlights an elevated prevalence of anemia and ID in particularly vulnerable Indigenous subpopulations in Canada. Our findings suggest that intervention fostering healthier food environments and traditional meat consumption as well as higher consumption of foods naturally rich in vita$\min \mathrm{C}$, which is known to enhance iron absorption, and fighting underlying causes of inflammation could decrease ID and anemia. Indeed, these findings raise the importance of better documenting this public health problem among First Nations youth across the country and call for preventive actions at multiple scales.

\section{Compliance with ethical standards}

This study was approved by the ethical boards of the CHU de QuébecUniversité Laval (no. C14-08-2105) and Health Canada (no. 2014-0043).

Conflict of interest The authors declare that they have no conflict of interest.

Open Access This article is licensed under a Creative Commons Attribution 4.0 International License, which permits use, sharing, adaptation, distribution and reproduction in any medium or format, as long as you give appropriate credit to the original author(s) and the source, provide a link to the Creative Commons licence, and indicate if changes were made. The images or other third party material in this article are included in the article's Creative Commons licence, unless indicated otherwise in a credit line to the material. If material is not included in the article's Creative Commons licence and your intended use is not permitted by statutory regulation or exceeds the permitted use, you will need to obtain permission directly from the copyright holder. To view a copy of this licence, visit http://creativecommons.org/licenses/by/4.0/.

\section{References}

Basile, S., Mchugh, N. G.-L., Patterson, E., Montambault, P., Schulze Senc, D., Sergerie, D., Mcdonald, G., et al. (2014). First Nations in Quebec and Labrador's Research Protocol [Internet]. AFNQL [cited 2018 Feb 26]. Available from: https:/www.cssspnql.com/ docs/default-source/centre-de-documentation/anglais_web.pdf? sfvrsn=2.

Caron-Beaudoin, É., Ayotte, P., Laouan Sidi, E. A., Gros-Louis McHugh, N., \& Lemire, M. (2019). Exposure to perfluoroalkyl substances (PFAS) and associations with thyroid parameters in First Nation children and youth from Quebec. Environment Internation [Internet], 128(December 2018), 13-23. https://doi.org/10.1016/j. envint.2019.04.029.

Cash, J. M., \& Sears, D. A. (1989). The anemia of chronic disease: spectrum of associated diseases in a series of unselected hospitalized patients. American Journal of Medicine [Internet], 87(6), 638-644 Available from: http://www.ncbi.nlm.nih.gov/pubmed/2589399.

Chan, L., Batal, M., Receveur, O., Sadik, T., Schwartz, H., Ing, A., et al. (2019). First Nations Food, Nutrition and Environment Study (FNFNES): results from Quebec (2016). Ottawa: University of Ottawa.

Christofides, A., Schauer, C., \& Zlotkin, S. H. (2005). Iron deficiency and anemia prevalence and associated etiologic risk factors in First Nations and Inuit communities in Northern Ontario and Nunavut. Canadian Journal of Public Health [Internet], 96(10), 304-307 Available from: http://www.ncbi.nlm.nih.gov/pubmed/19668671. Dec [cited 2016 Dec 11].

Cole, T. J., Faith, M. S., Pietrobelli, A., \& Heo, M. (2005). What is the best measure of adiposity change in growing children: BMI, BMI \%, BMI z-score or BMI centile? European Journal of Clinical Nutrition, 59(3), 419-425.

Cooper, M., Greene-Finestone, L., Lowell, H., Levesque, J., \& Robinson, S. (2012). Iron sufficiency of Canadians. Health Reports, 23(4), 4148. 
de Benoist, B., McLean, E., Egli, I., \& Cogswell, M. (2008). Worldwide prevalence of anaemia 1993-2005. WHO Global Database on Anaemia.

Engle-Stone, R., Aaron, G. J., Huang, J., Wirth, J. P., Namaste, S. M., Williams, A. M., et al. (2017). Predictors of anemia in preschool children: Biomarkers Reflecting Inflammation and Nutritional Determinants of Anemia (BRINDA) project. The American Journal of Clinical Nutrition, 106(June), 402-415.

Fishman, S. M., Christian, P., \& West, K. P. (1999). The role of vitamins in the prevention and control of anaemia. Public Health Nutrition, $3(2), 125-150$.

Government of Canada (2014) Quebec Indigenous Community profiles [Internet]. [cited 2017 Mar 13]. Available from: https://www.aadncaandc.gc.ca/Mobile/Nations/NationsAltMap-eng.html

Gruys, E., Toussaint, M. J. M., Niewold, T. A., \& Koopmans, S. J. (2005). Acute phase reaction and acute phase proteins. Journal of Zhejiang University Science B [Internet], 6(11), 1045-1056 Available from: http://www.ncbi.nlm.nih.gov/pubmed/16252337. [cited 2017 May 17].

Hegazy, A. A., Zaher, M. M., Abd El-Hafez, M. A., Morsy, A. A., \& Saleh, R. A. (2010). Relation between anemia and blood levels of lead, copper, zinc and iron among children. BMC Research Notes, $3(133)$.

Hinnouho, G.-M., Barffour, M. A., Wessells, R., Brown, K. H., Kounnavong, S., Chanhthavong, B., et al. (2018). Comparison of haemoglobin assessments by HemoCue and two automated haematology analysers in young Laotian children. Journal of Clinical Pathology [Internet], 71, 532-538. https://doi.org/10. 1136/jclinpath-2017-204786 [cited 2018 Sep 11].

Hooper, D., Coughlan, J., \& Mullen, M. R. (2008). Structural equation modelling: guidelines for determining model fit structural equation modelling: Guidelines for determining model fit. Electronic Journal of Business Research Methods [Internet], 6(1), 53-60 Available from: www.ejbrm.com

Hurrell RF (2012) Influence of inflammatory disorders and infection on iron absorption and efficacy of iron-fortified foods. Vol. 70, Nestle Nutrition Institute workshop series. p. 107-16.

INSPQ. The Diet of Québec First Nations and Inuit Peoples [Internet]. 2015 [cited 2017 Mar 17]. Available from: https://www.inspq.qc.ca/ pdf/publications/2065_diet_first_nations_inuits.pdf

Jamieson, J. A., \& Kuhnlein, H. V. (2008). The paradox of anemia with high meat intake: a review of the multifactorial etiology of anemia in the Inuit of North America. Nutrition Reviews, 66(5), 256-271.

Jamieson, J. A., Weiler, H. A., Kuhnlein, H. V., \& Egeland, G. M. (2012). Traditional food intake is correlated with iron stores in Canadian Inuit men. The Journal of Nutrition, 142(4), 764-770.

Jamieson, J. A., Weiler, H. A., Kuhnlein, H. V., \& Egeland, G. M. (2016). Prevalence of unexplained anaemia in Inuit men and Inuit postmenopausal women in Northern Labrador: International Polar Year Inuit Health Survey. Canadian Journal of Public Health [Internet], 107(1), e81-e87 Available from: http://journal.cpha.ca/index.php/ cjph/article/view/5173.

Kelly-Scott, K., \& Smith, K. (2015). Les peuples autochtones. Feuillet d'information du Canada [Internet] [cited 2018 Apr 30]. Available from: http://www.statcan.gc.ca/pub/89-656-x/89-656-x2015001fra.pdf.

Lane, D. J. R., \& Richardson, D. R. (2014). The active role of vitamin C in mammalian iron metabolism: much more than just enhanced iron absorption! Free Radical Biology and Medicine, 75, 69-83.

Lopez, A., Cacoub, P., Macdougall, I. C., \& Peyrin-Biroulet, L. (2016). Iron deficiency anaemia. Lancet, 387(10021), 907-916.

Nachtigall, C., Kroehne, U., Funke, F., \& Steyer, R. (2003). (Why) should we use SEM? Pros and cons of structural equation modeling. Methods of Psychological Research, 8(2), 1-22.

Nordengberg, D., Yip, R., \& Binkin, N. J. (1990). The effect of cigarette smoking on hemoglobin levels and Anemia screening. JAMA, the Journal of the American Medical Association, 264(12), 1-4.

Pacey, A., Weiler, H., \& Egeland, G. M. (2011). Low prevalence of irondeficiency anaemia among Inuit preschool children: Nunavut Inuit Child Health Survey, 2007-2008. Public Health Nutrition [Internet], 14(8), 1415-1423 Available from: http://www.ncbi.nlm. nih.gov/pubmed/20920385. [cited 2016 Aug 24].

Plante, C., Blanchet, C., Rochette, L., \& O'Brien, H. T. (2011). Prevalence of anemia among Inuit women in Nunavik, Canada. International Journal of Circumpolar Health, 70(2), 154-165.

Sears, D. A. (1992). Anemia of chronic disease. Medical Clinics of North America [Internet], 76(3), 567-579 Available from: http://www. ncbi.nlm.nih.gov/pubmed/1578957. [cited 2017 Apr 28].

Shim, J.-S., Oh, K., \& Kim, H. C. (2014). Dietary assessment methods in epidemiologic studies. Epidemiol Health, 36(e2014009), 1-8.

St-Amand A (2017) Canadian Health Measures Survey: 10 years of biomonitoring [Internet]. [cited 2018 Feb 19]. Available from: https:// nb.lung.ca/cnhhe/wp-content/uploads/2017/11/CNHHE-CHMS Final.pdf

Statistics Canada (2017) Aboriginal peoples in Canada: key results from the 2016 Census [Internet]. The Daily. Available from: http://www. statcan.gc.ca/daily-quotidien/171025/dq171025c-eng.pdf

Teni, M., Shiferaw, S., \& Asefa, F. (2017). Anemia and its relationship with academic performance among adolescent school girls in Kebena district. Southwest Ethiopian Biotechnology Health Science, 4(1), 1-8.

Turgeon O’Brien, H., Blanchet, R., Gagné, D., Lauzière, J., \& Vézina, C. (2016). Using soluble transferrin receptor and taking inflammation into account when defining serum ferritin cutoffs improved the diagnosis of iron deficiency in a group of Canadian preschool Inuit children from Nunavik. Anemia [Internet], 2016, 6430214 Available from: http://www.hindawi.com/journals/anemia/2016/ 6430214/.[cited 2018 Feb 26].

Turkoski, B. (2003). Tired blood? Orthopaedic Nursing, 22, 222-227.

WHO (2001) Iron Deficiency Anaemia: Assessment, Prevention and Control, A guide for program managers [Internet]. A guide for programme mangers. Available from: http://www.who.int/nutrition/ publications/en/ida_assessment_prevention_control.pdf. Accessed 1 Mar 2019.

Publisher's note Springer Nature remains neutral with regard to jurisdictional claims in published maps and institutional affiliations. 